\title{
Applying Emotional Intelligence Skills to Leadership and Decision Making in Non-Profit Organizations
}

\section{James D. Hess ${ }^{1, *}$ and Arnold C. Bacigalupo ${ }^{2}$}

1 Department of Family Medicine, Oklahoma State University Center for Health Sciences, 1111 W 17th St. Tulsa, OK 74107, USA

2 Voyageur One, Oakbrook, IL 60181, USA; E-Mail: acbaci@ gmail.com

* Author to whom correspondence should be addressed; E-Mail: jim.hess@ okstate.edu; Tel.: +918-561-8215; Fax: +918-561-1279.

Received: 8 August 2013; in revised form: 21 October 2013 / Accepted: 24 October 2013 / Published: 4 November 2013

\begin{abstract}
Non-profit organizations and leaders may benefit from the utilization of behaviors attributed to emotional intelligence. The consideration of emotional intelligence skills becomes a strategy for the development of the non-profit organizational leader's ability to assess the impact and consequences of decisions, while simultaneously improving the quality and effectiveness of the decision-making process. The purpose of this paper is to identify how emotional intelligence skills can be applied to enhance the leadership decision-making processes within the non-profit organization. Goleman's (2001) and Boyatzis' et al. (2000) four essential elements of emotional intelligence and their associated 20 behavioral competencies are utilized to develop a methodology for the practical application of emotional intelligence skills to leadership decision-making within the non-profit organization. A checklist of questions and observations is provided to assist non-profit leaders in the improvement of emotional intelligence awareness, as well as the application of emotional intelligence skills to decisions and decision-making processes.
\end{abstract}

Keywords: non-profit organization; leadership; emotional intelligence; decision-making 


\section{Introduction}

One conspicuous feature of Western societies has been the increasing employment of non-profit organizations, the so-called third sector, for the delivery of needed goods and services to the population [1]. This reliance on non-profit organizations for the support of Western economies and cultures has created a significant amount of pressure on the leadership of those organizations. Kramer noted that large or small, most non-profit organizations are unusually dependent on the quality of their executive leadership [2]. Additionally, Lane and Wallis concluded that the comparative institutional advantage of non-profit organizations comes from the leadership function; specifically that leadership is crucial for handling the constant commitments and changes needed for the non-profit organization's long-term viability [1].

In large measure the leaders of today's non-profit organizations function as the managers of knowledge-based entities, creating and implementing solutions to complex problems and ever changing circumstances. Milkman et al. noted in the knowledge-based economy, a knowledge worker's primary deliverable is a good decision [3]. As the head of a knowledge-based entity, the non-profit leader is faced with the responsibility of delivering the best possible decision to achieve or further the mission of the non-profit enterprise. The ability of non-profit organizations to contemplate, evaluate and implement quality decisions is dependent upon a multitude of intrinsic and extrinsic factors. While the management of extrinsic variables may be more difficult to control, the identification and management of human variables such as emotion and logic are pivotal in the effort to increase the quality of decisions and decision-making processes.

Researchers have recently focused attention on the impact of some of the human emotion variables on decision making. Hilary and Hui found that both individuals and organizations exhibiting a high degree of religiosity display lower levels of risk exposure in decision making [4]. Similarly, Fernando and Jackson noted that in the individuals studied outcomes of difficult decisions, both good and bad, were in some way attributable to a religious, spiritual or value characteristic [5].

One of the most fascinating dichotomies in contemporary thought surrounding decision-making is the apparent conflict between the roles of emotion and rationality. Stanovich and West divided cognitive functions between those that were faster, effortless, implicit and emotional as compared to those that were slower, conscious, explicit and logical [6]. The authors believed better decisions could be derived by shifting decision-makers from intuitive and emotional thinking to logical and rational thinking. Moreover, the authors concluded replacing intuition with more intensive data collection and analytical processes enabled the decision-maker to construct linear models to produce relevant predictors. The suggestion here is that human beings will make better decisions if we transform our cognitive functions to resemble those of an emotion-free microprocessor.

There is an alternate research process proceeding in artificial intelligence to inject learned emotions into microprocessor driven decision-making. IBM has developed a cognitive computing processor to emulate the patterns of human thinking [7]. Additionally, the MIT Artificial Intelligence Laboratory has developed an artificially intelligent machine that defines elements of sensory and emotional systems [8]. The computerized platform is capable of modeling six different emotions for decision-making: anger, fear, distress/sadness, joy/happiness, disgust and surprise [8]. Velasquez's premise based upon Damasio's 
previous work is that intuition and emotions play crucial roles in the ability to make smart, rational decisions [9].

Thus the ironic dichotomy of current thought is that some researchers believe leaders will make better decisions when emotions are removed, and the mind is bent to perform more like a data-analyzing machine. Alternatively, some researchers contend data-analyzing machines will make better decisions when they are capable of utilizing intuition and emotions. So who is right? We believe both are fundamentally correct. Further, we have concluded, consistent with Simon's notion that emotion and rationality are inextricably linked, emotional intelligence can serve as the necessary bridge between the two $[10,11]$. Moreover, the behaviors most often identified with emotional intelligence may be learned and applied in a practical manner to improve the overall quality of decisions and decision-making processes within the non-profit setting.

\section{Purpose of Paper}

Emotional intelligence has been the subject of a significant amount of literature over the past two decades, ranging from debate over whether emotional intelligence is innate or learned, to the categorization of specific behaviors that define emotional intelligence. However, little has been contributed to how the behaviors associated with emotional intelligence may serve as a lens from which to view decision-making within the non-profit environment. The purpose of this paper is to review relevant emotional intelligence and decision-making literature and to provide a checklist to assist non-profit leaders in the improvement of emotional intelligence awareness, as well as to enhance decisions and decision-making processes.

\section{Leadership and Decision-Making}

Goleman et al. provided greater insight into the integration of emotional intelligence attributes in leadership with their distinction of resonant and dissonant styles [12]. The authors described the dissonant leader as one who fails to connect with others, is insensitive to others' reactions and creates distance between themselves and followers. In the work setting, the business and emotional impact of the dissonant leader is that people are off balance, disconnected from leadership and perform poorly [12]. Conversely, Goleman et al. describe the resonant leader as one who is attuned to people's feelings and moves them in a positive emotional direction [12]. Additionally the resonant leader is able to strike a chord in followers, making them feel inspired and uplifted [12]. The authors conclude the resonant leadership style relies fundamentally on the attributes of emotional intelligence to connect with followers in creating a positive and productive work environment.

The notion of whether leadership competencies differ between for-profit and non-profit disciplines has been addressed albeit minimally within the literature. Thach and Thompson found that for-profit and non-profit leaders were similar in their valuing of honesty, collaboration and developing others [13]. Differences however did exist between the sectors in the valuing of time management, self knowledge, inspiration and conflict management. The authors found for-profit leaders were more likely to value the leadership competencies of time management and self knowledge, while non-profit leaders were more likely to value conflict management and being inspirational [13]. 
Arguing the issue of differences in the decision-making process between non-profit and for-profit organizations, Freeman noted that while for-profit leaders may be sensitive to the needs of stakeholders, those leaders believe their primary responsibility is to ensure profits and maximize shareholder wealth [14]. Chandler noted for-profit organizations have more clear-cut criteria for the measurement of failure and success [15]. Pfeffer concluded that while both non-profit and for-profit leaders are required to be rational, analytical and political, for-profit leaders may focus their utilization of power on the consensus goal of profit maximization [16]. Lindbolm concluded the primary difference in decision-making in the public sector is driven by the need to balance the needs of multiple constituents, resulting in decisions made through a process of "partisan mutual adjustment" [17].

Schwenk studied the effects of conflict in decision-making processes to ascertain whether differences existed between for-profit and non-profit organizations [18]. The study revealed that conflict occurred earlier in the non-profit organizations and was viewed as an analytical tool. For-profit entities were more likely to see conflict as a means to temporary compromise. Additionally, for-profit managers saw the conflict process in decision-making as confusing and adding little value to the process [18].

The foundation of leadership power and decision-making authority within the non-profit organization begins with the board. Carver concluded while non-profit boards are made up of volunteers, the accountability of the organization ultimately depends upon the board's and management's ability to embrace the governance concept [19]. Simply stated, while the board is responsible for the governance of the organization, day-to-day operations and execution of the board's vision is the responsibility of management. Carver described optimal non-profit board leadership as "ownership one step down, rather than management one step up" [19]. With regard to decision making, Carver concluded non-profit boards will delegate powerfully and safely to those who effectively carry out the work of the organization as long as those individuals recognize and embrace the ultimate accountability and authority of the board [19].

\section{Non-Profit Leadership and the Case for Emotional Intelligence}

Leaders within non-profit organizations are required to fulfill a number of roles simultaneously, including inspirer, developer and change agent. As inspirer, the non-profit leader's role is crucial in inducing stakeholders to make commitments of time, effort and wealth for the advancement of the organization's goals [1]. Lane and Wallis noted non-profit leaders must make decisions on the appropriate leadership style to sustain a climate of hope among their stakeholders [1]. The appropriate decision on leadership style will lead to successful interactions, encouraging stakeholders to reinvest their emotional energy in subsequent endeavors [20]. Thus decision-making ability and the factors affecting decision-making are pivotal to the non-profit leader's success.

As developer, the non-profit leader must be willing to exercise judgments that will allow followers to take initiative and accept responsibility for the organization's development. This is often reflected in the emergence of mentoring relationships between leaders and followers in the non-profit organization [21]. Lane and Wallis noted even where followers actively participate in deliberations about organizational development, they will tend to look to leaders to have the "final word" [1]. In these instances the non-profit leader is required to make decisions or judgments that manage the expectations of external stakeholders 
as well as the emotions of the internal organizational followers. Managing and balancing these interests is the basis of emotional intelligence in decision-making.

As change agent, the non-profit leader is confronted with the numerous challenges of creating and sustaining major organizational change. Regulatory, economic and technological changes have forced non-profit organizations to adapt quickly and effectively, putting a premium on executive leadership that is capable of facilitating organizational change [22]. Lane and Wallis concluded non-profit leaders are required to make decisions that affect an organization's direction, thereby distinguishing the difference between managing and leading [1]. Tichy and Devanna noted change leadership involves pulling an organization into the future by creating a positive view of what the organization can become, while simultaneously providing emotional support for individuals during the transition process [23]. Accordingly, initiating and managing organizational change requires the non-profit leader to make decisions based upon both logic and emotion, a skill that requires emotional intelligence.

While we contend the consideration of issues through the lens of emotional intelligence can enhance the quality of decisions and decision-making processes, it does not represent a panacea for the non-profit leader. Each non-profit organization is unique with its own set of distinct challenges, and the environmental setting in which the non-profit leader must work will determine the appropriate skill set necessary for success. At some level though the assessment of this environment and the relevant lens from which to view institutional challenges is itself an emotional intelligence skill.

\section{Relevant Emotional Intelligence Research}

The bulk of the literature defining emotional intelligence may be encapsulated in the description of three models: (1) ability model; (2) trait model; and (3) mixed model. The ability model as described by Salovey and Grewal posited that individuals have varied abilities to process and react to emotional circumstances and as a result develop adaptive behaviors to deal with social situations [24]. The trait model proposed by Petrides et al. was based upon the premise emotional intelligence represents a cluster of self perceptions operating at the lower levels of personality [25]. This focus on behavioral dispositions relied heavily on self measurement and as such was more resistant to scientific calibration [25]. The mixed model was best characterized by Goleman's description of emotional intelligence as a wide array of competencies and skills driving leadership performance [26]. Goleman's model was based on the premise emotional competencies are not innate traits, but rather learned skills that may be developed and improved [26].

In a follow-up study Goleman noted the very best corporate leaders, while diverse in their leadership styles, share in common the characteristics of self awareness, self regulation, motivation, empathy and social skill [27]. These skills, according to Goleman, allow superb leaders to understand their own as well as others' emotional makeup well enough to move people to accomplish institutional objectives [27]. Goleman's original work on emotional intelligence described the following essential elements or abilities: (1) knowing one's emotions; (2) managing one's emotions; (3) motivating oneself; (4) recognizing emotions in others; and (5) handling relationships [26]. Goleman's theory of emotional intelligence and its characteristic behaviors has been further refined to include both individual and organizational behaviors and outcomes [28]. The more fully developed emotional intelligence model as described by Goleman and Boyatzis et al. refined the original five elements into 
four dimensions and further subdivided these characteristics into 20 behavioral competencies as outlined in the following table [28,29].

The domain of emotional intelligence has also benefited from more recent literature in the leadership and group dynamics disciplines. Taylor et al. noted both aspiring and established leaders in the organizations they studied agreed the behaviors associated with emotional intelligence were characteristics of effective leaders and critical to the future success of aspiring leaders [30]. The authors noted an additional function in established leaders described as organizational altruism or more specifically defined as an understanding of the institution and dedication to the institution's success. Wang and Haung found emotional intelligence and group cohesiveness were positively associated with transformational leadership [31]. In detailing the relevance and efficacy of emotional intelligence, Antonakis et al. concluded relationship approaches to leadership were inherently emotional, making emotional intelligence an integral part of the leadership process [32]. Similarly, Dasborough and Ashkanasy argued leader/member exchange relationship quality was enhanced through emotional intelligence of leaders, and Zhou and George concluded emotional intelligence can enhance leadership within team settings [33,34].

In separate studies, Kouzes and Posner as well as Wheatley, describe successful leadership traits as understanding one's own emotions as well as those of others $[35,36]$. The authors noted that successful leaders utilize those traits to connect with others to inspire, motivate and challenge them $[35,36]$. Langley compared senior managers with middle managers targeted for promotion and found that senior managers exhibited significantly higher levels of emotional intelligence traits, supporting the notion that emotional intelligence was an important tool for measuring promotional readiness [37]. Further, Dulewicz and Higgs concluded in a seven-year longitudinal study that emotional intelligence was significantly more important that intellect in the advancement of managers [38].

The literature provides additional insight into the role emotional intelligence plays within non-profit organizations. Moore described the cultural assets of non-profit entities as unique, concluding that the strengths of those organizations include a work climate with high levels of emotional intelligence [39]. Further linking the study of emotional intelligence and leadership within the non-profit sector, Hawkins and Dulewicz examined the relationship between emotional intelligence and governance in the public sector, providing specific examples on the potential positive impact of emotional intelligence skills on community policing [40]. In a study of non-profit board chairs, Harrison and Murray concluded emotional intelligence was an attribute in the overall perception of board chair effectiveness [41]. In subsequent studies, Harrison et al. demonstrated board chairs who possessed higher levels of emotional and/or spiritual intelligence were more likely to be seen as effective in building relationships with key players within the organization and were perceived as having a greater impact on the CEO and other board members [42,43]. The authors concluded board chairs with emotional and spiritual intelligence attributes were seen as team leaders working "with" rather than "over" others $[42,43]$. Morehouse studied the significance of emotional intelligence traits across career arenas and concluded that leaders in the non-profit health and human service sectors exhibited higher levels of emotional intelligence than their counterparts in the profit world [44].

Addressing the role of emotional intelligence in decision-making processes, Sevdalis et al. noted that although empirical research has emphasized the relevance of emotions in decision-making processes, individual differences in the perception and experience of emotion have been largely 
overlooked [45]. The authors concluded when people make decisions they often think about the emotions the outcomes are likely to trigger. Further, Sevdalis et al. outlined decision-makers: (1) anticipate their emotions before a decision materializes; (2) experience them when they receive the outcomes of their decision; and (3) recall them from memory when they contemplate past decisions (good or poor) [45]. Mellers et al. concluded emotions people expect to experience or have experienced as a result of their decisions are important determinants of their current and future behavior [46]. Winter and Kuiper noted individuals differ in systematic ways in how they experience emotions, how they differentiate among emotions and how much emotional information they can process [47].

Finally, the measurement of emotional intelligence has been addressed over the past two decades through the development of a number of instruments and assessment processes. The most ubiquitous of these measurements in the literature are the following instruments:

(a) Mayer-Salovey-Caruso Emotional Intelligence Test (MSCEIT) developed by Mayer, Salovey and Caruso [48];

(b) Emotional Competency Inventory (ECI) developed by Boyatzis, Goleman and Rhee [49]; and

(c) Emotional Quotient Inventory (EQ-i) developed by Bar-On [50].

\section{Applying Emotional Intelligence Skills to Non-Profit Leadership and Decision-Making}

While much of the literature has focused on the theoretical aspects of emotional intelligence, a significant gap exists in the practical application of these skills to decision-making in general and more specifically to decision making by non-profit leaders. Given that the literature supports the notion non-profit leadership differs markedly from its for-profit analog, it follows that successful decision-making processes within non-profit organizations might also be distinct. Leaders as decision makers in non-profit organizations are often faced with problems that cannot be easily solved and in some cases have negative impacts on some constituency even when they have been declared solved. Thus the consideration of the effect of decisions on others should be an important element of the decision-making process for the non-profit organizational leader. While determining "who" will be affected by decisions may be a more pragmatic function requiring rationality and logic, determining "how" the decision will be interpreted and its subsequent effect on constituents of the non-profit organization requires the skills associated with emotional intelligence. If one believes emotional intelligence adds value to the individual and/or group decision-making process, the question arises how can it be practically applied to achieve that desired result?

The practical application of the ability model described by Salovey and Grewal necessitates the exercise of the following skills: (1) perceiving emotions; (2) using emotions; (3) understanding emotions; and (4) managing emotions [24]. In the non-profit decision-making process, the acknowledgment of individual emotions is critical in determining not only the motivations behind decisions but also the impact of those decisions on both internal and external stakeholders. Decision makers (both management and governance) in non-profit organizations who understand the emotions of others may utilize that perceptivity to head off potential negative outcomes by addressing those emotional issues in advance of the decision [51]. Likewise, non-profit leaders who perceive and understand their own emotions will be much more effective in managing those emotions in the 
decision-making process. In keeping with the four elements described by Goleman and Boyatzis et al., the emotional intelligence skills in decision making by non-profit leaders may be categorized as those more related to the individual, self awareness and self management, and those more attributable to the individual's relationship and interaction with others, social awareness and relationship management $[28,29]$.

\section{Self Awareness and Self Management}

Self awareness and its representative competencies of accurate self assessment and self confidence (Table 1) enable emotionally intelligent non-profit leaders/decision-makers to determine their appropriate role in the decision-making process [28,29]. Specifically, these skills enable decision makers to determine if they have the requisite orientation to a problem and have enough self confidence to assess their own decision-making skills in comparison to others. Accordingly, these emotional intelligence skills create a decision path to determine who is the most appropriate person or group to make the best decision in any given circumstance. Without emotional intelligence, non-profit leaders/decision makers, e.g., the board or CEO, fail the first and most important decision, which is "who is the best decision-maker for this decision?"

Table 1. Dimensions of emotional intelligence and associated behavioral competencies *.

\begin{tabular}{cccc}
\hline \multicolumn{2}{c}{ Individual } & \multicolumn{2}{c}{ Individual Relationship and Interaction with Others } \\
\hline Self Awareness & Self Management & Social Awareness & Relationship Management \\
\hline Self Confidence & Self Control & Empathy & Developing Others \\
Accurate Self Assessment & Trustworthiness & Service Orientation & Influence \\
& Conscientiousness & Organizational Awareness & Communication \\
& Adaptability & Empathy & Conflict Management \\
& Achievement Drive & & Leadership \\
& Initiative & Change Catalyst \\
& & & Building Bonds and \\
& & Teamwork \\
& & Collaboration \\
\hline
\end{tabular}

* Goleman and Boyatzis et al. [28,29].

Self management and its behavioral components of self control, trustworthiness, conscientiousness, adaptability, achievement drive and initiative (Table 1) are equally important emotional intelligence attributes for non-profit leaders/decision-makers [28,29]. Lerner and Shonk documented the effects of residual anger on decision-making, noting that decision-makers who were held accountable for their decisions were better at managing the effects of their anger [52]. Controlling the impulse to make every decision individually can sometimes fly in the face of the need to show initiative and achievement [53].

Additionally, in order for non-profit leaders/decision makers to gain moral authority on an issue, they must first be viewed as trustworthy by those affected by a decision. Trust is earned over time through a process of openness and honesty in both communications and relationships. Emotionally intelligent non-profit leaders utilize self management skills to establish a consistent record of achievement and emotional control, while simultaneously earning trust from both internal and external constituents. 
In settings where the speed at which technical issues can be resolved or new services, applications or solutions can be made available to the non-profit constituent is highly valued, the temptation is to avoid decision-making processes which occupy valuable time. However, the emotionally intelligent non-profit leader will evaluate the consequences of losing trust among workers and teams when speed wins out over participation [53]. Time spent on developing the right decision-making process will pay large dividends in both the quality of solutions, as well as the level of acceptance and trust gained.

Emotionally intelligent non-profit leaders are no doubt driven by rewards other than monetary gain. This orientation however should not be confused with a lack of initiative or drive, since both traits are obviously required to ascend to a position of leadership. Individuals in leadership positions are often called upon to balance two very distinct self motivations. On one hand they must exhibit initiative and drive to acquire and hold a position of authority. One the other hand they must be willing to sublimate their self confidence successfully and accurately assess their ability to effectively manage a decision-making process. This circumstance also requires the trait of adaptability in that the emotionally intelligent leader must be willing and able to view their own decision-making abilities in the same objective manner in which they would evaluate others. Accordingly, leaders must suppress their need for personal achievement and rely on adaptability to assess the best decision-making process for each circumstance and be conscientious in engaging the appropriate individuals and groups.

\section{Social Awareness and Relationship Management}

The awareness and consideration of relationships and the impact of those relationships on decisions is an important element in the decision-making process. Indeed the manner in which decisions are perceived by others is pivotal to a successful decision outcome. Recall that the resonant leadership style outlined by Goleman et al. described emotionally intelligent leaders as attuned to the feelings of others and able to strike an inspirational chord in followers [12]. These social awareness and relationship skills provide a useful lens from which to view decision-making. The emotional intelligence skill of social awareness and its core competencies of empathy, service orientation and organizational awareness (Table 1) enable non-profit leaders/decision makers to judge the impact of not only their decisions but also the manner in which those decisions are made $[28,29]$.

The best decisions are those that can be understood and accepted by the individuals most affected by the decision. Whether they are individuals or groups, non-profit leaders/decision makers who practice the value of empathy can foresee the impact of their decisions before implementation [28]. Likewise, exhibiting a servant philosophy can improve the quality of decisions, particularly within the non-profit organization. For example, if non-profit leaders/decision makers view those affected by decisions as customers who may be retained or lost, they may be more likely to consider the outcomes and consequences of decisions [54]. Accordingly, decisions considered in the context of service outcomes, as well as customer satisfaction and retention, are more likely to be understood and more easily defended within the non-profit organization.

Values and cultural mores are an integral part of an organization's fiber and this particularly true within the non-profit setting. In instances of leadership change or transition, it is vital to the success of new leaders that they carefully assess the organizational culture prior to embarking upon the implementation of major decisions. In organizations with long-term sustained leadership it is equally 
important that incumbent leaders consistently and continually monitor the culture of the entity to stay abreast of shifts and trends in the internal environment. This awareness of the non-profit organization's culture will enable leaders to make more rational judgments in decisions, as well as the processes by which the decisions are made. Moreover, it will enable non-profit leaders to best determine the appropriate timing and communication of their decisions.

As noted previously in Table 1, the emotional intelligence skill of relationship management includes the behavioral competencies of developing others, influence, communication, conflict management, leadership, change catalyst, building bonds and teamwork and collaboration [28,29]. The enhancement of non-profit decision-making processes is dependent upon the ability of leaders to effectively communicate desired outcomes, influence stakeholders and manage conflict. In decision-making processes within the non-profit organization, the ability to manage relationships is pivotal to success.

Emotionally intelligent leaders within the non-profit setting recognize their strengths and weaknesses and surround themselves with those who mitigate or complement those attributes. Additionally, these leaders exhibit the trait of developing others not just for the benefit of the organization but also for the professional and personal growth of the individuals themselves. For example, the emotionally intelligent CEO feels a responsibility to develop the talents of those within his/her direct reporting structure so as to prepare and ready them to serve as a future CEO. Rather than feeling threatened by the individuals under them, CEO's concerned about relationship management will develop those individuals into executives ready for an advanced position either inside or outside the current setting. This attribute entails developing the decision-making skills of those individuals and providing a framework for the instruction of emotional intelligence behaviors in decision-making.

The relationship management competency of influence implies emotionally intelligent leaders will utilize their personal and behavioral traits to impact decision-making processes. While personal charisma is the most widely thought of trait in this regard, influence may also be successfully exerted through other behaviors. For instance, in a non-profit setting where technical skills and knowledge are highly valued, influence in decision-making is best exercised by serving as a content expert on specific issues. In settings where social and psychological expertise are more heavily relied upon, influence is best exemplified through the demonstration of empathy and compassion. It is worth noting here that in most settings the application of an emotional intelligence trait in one area is easily transferred to another. Thus while empathy is a trait most identified with social awareness, it is readily applicable to the relationship management domain.

Even the best of decisions can have negative results if not properly communicated, including the proper articulation of decision-making processes. The emotionally intelligent nom-profit leader must view the successful communication of a decision as equally important as the decision itself. This process begins with a dialogue about the context of the need for a decision. When circumstances are fully discussed among the stakeholders, space is created, making room for the decision-making process to begin. Creating this dialogue and space is the process by which leaders can effectively utilize emotional intelligence skills to build consensus and increase the bonds among team members. The communication of the path the decision-making process will follow allows leadership to avoid the pitfalls of team members feeling distant and isolated from a decision and its impacts.

While most would like to believe the decision to affect change within the non-profit organization is most often arrived at through a rational, logical process that is not always the case. Indeed the 
implementation of many desired changes within the non-profit organization is fraught with potential conflict, regardless of the original intent of the change. The effectiveness of the non-profit leader is partially contingent upon their ability to exercise a leadership style that embraces the skills of conflict management. Recall that Harrison et al. found that non-profit board chairs who were perceived by others as effective were also seen as being able to successfully manage conflict [41-43]. The ability to manage conflict is central to both the process and outcome of decisions, requiring non-profit leaders/decision makers to exercise emotional skills while simultaneously attempting to steer necessary changes.

Building bonds, teamwork and collaboration in the decision-making process all require the emotionally intelligent leader to exhibit the behavior of limiting self desires for the benefit of a greater goal. One of the most effective methods of demonstrating this skill is to assign a decision-making process to a subordinate and then serve as a team member under that subordinate. This method requires the leader to learn to function as a team member just as others do within the non-profit organization. This exercise, while difficult for some at the outset, makes clear to those within the organization that leadership is truly dedicated to the principles of team and collaboration and is willing to allow others to demonstrate and develop their own decision-making skills.

\section{Emotional Intelligence Skills in Decision-Making Checklist}

Applying the skills of emotional intelligence to non-profit leadership and decision-making situations can vastly improve the quality of decisions. In keeping with Goleman et al.'s description of resonant leadership, non-profit leaders/decision makers might consider and utilize the following checklist of questions and observations to enhance both decision-making and decision-making processes [12].

(1) Are non-profit leaders/decision makers aware of their leadership and decision-making skills and styles? Is there a tendency to reach first for the emotional elements of a decision circumstance, or conversely, to reach for the rational analysis components? Emotionally intelligent non-profit leaders/decision makers will make an honest self assessment of skills and styles, noting the differences in their behaviors and abilities as compared to others.

(2) Would others describe non-profit leaders/decision makers as inclusive or exclusive in decision-making processes? The leadership and decision-making styles as described by Vroom and Yetton are useful here [55]. The authors described a range of behaviors beginning with the pure autocratic style, to partial inclusion and pure delegation. While non-profit leaders/decision makers may view themselves as more democratic or participatory, the more critical aspect is the perception of others. While it may not be appropriate to be inclusive in every decision, the emotional intelligence function suggests it is important to communicate to others when and why inclusive or exclusive methodologies are utilized.

(3) Are non-profit leaders/decision makers confident in their decision-making skills? Tsai and Young concluded that fear makes individuals second-guess themselves and abandon support for efforts that have gone even slightly off track [56]. Emotionally intelligent non-profit leaders/decision makers must exude confidence in their decision-making style. Being self 
aware also implies acknowledging one's weaknesses and having the confidence to recognize the strengths of others in decision-making. Self awareness also includes the skill of recognizing the impact of one's styles and behaviors on others.

(4) Are non-profit leaders/decision makers merely focused on their own interests or are they truly interested in achieving the best decision results? Harrison and Murray documented that effective board chairs possessed the attribute of being mission centered while less effective chairs were more focused on the advancement of their personal career or agenda $[42,43]$. Thus, emotionally intelligent non-profit leaders/decision makers are characterized by their ability to suppress their own desires and interests for the common good.

(5) What individuals, groups or constituents will be most affected by the decision? Wanberg and Banas concluded that those impacted by a decision will perceive the change more positively if they are involved in the decision-making process [57]. This involvement my range from active participation in the contemplation of decision options to commenting before a decision is finalized. Social awareness implies non-profit leaders/decision makers have adequately contemplated the impact and consequences of a decision before it is made. This emotional intelligence skill requires non-profit leaders/decision makers to play out scenarios of decisions to determine both their short and long-term consequences and effects [51].

(6) Are non-profit leaders/decision makers overly focused on the desire for a speedy result? Bazerman and Malhotra noted that time pressures often lead decision makers to bad judgments. Patience is pivotal in achieving the desired decision outcome [53]. The emotionally intelligent non-profit leader will evaluate the consequences of losing trust among workers and teams when speed wins out over participation [53].

(7) How will the decision and decision-making process be viewed in retrospect? Emotionally intelligent decision-making within the non-profit organization requires looking forward and backward simultaneously. Viewing actions from a historical perspective enables non-profit leaders/decision makers to assess the impact of current decisions through the eyes of constituents. Reliving past decisions through the lens of their impact also assists emotionally intelligent non-profit leaders/decision makers in playing out the future of current contemplated actions.

(8) How can a decision-making process be utilized to build trust, not only for decision makers, but also among all the appropriate constituents of the non-profit organization? Graen and Uhl-Bien theorized in leader-member exchange that leaders were perceived to be more effective due to the quality of the relationships with followers [58]. Harrison et al. similarly found that board chairs who exhibited attributes of emotional intelligence were more likely to be perceived by key actors with whom they interact as having high quality relationships $[42,43]$. Mayer and Caruso noted that leaders high in emotional intelligence will build real social fabric within an organization, as well as between the organization and those it serves [59]. Interpreted in the leadership and decision making environment, this social fabric is best described as furthering and honoring the culture of the organization. 
Accordingly, emotionally intelligent decisions are those that are grounded in the culture of the non-profit organization.

(9) How do non-profit leaders/decision makers communicate with others engaged in the decision-making process? This aspect of relationship management requires a regular and consistent method of communication that reinforces the role of each person in the decision-making process. It is important to remember that individuals differ in their preferred communication method. Thus the emotionally intelligent leader is able to discern which team members require face-to-face dialogue from those that prefer written communication. An inappropriate communication method can effectively unravel a successful decision-making process.

(10) Are non-profit leaders/decision makers willing to adapt to new decision-making processes rather than relying upon the entrenched processes of the past? When the need for a new decision-making process arises, those who can self manage and correct course will earn the trust of those involved in the process. The honest acknowledgement of a need to break with the practices of the past is critical to building self confidence, as well as developing the relationships necessary to affect a positive decision result [51].

(11) Are non-profit leaders/decision makers willing to quickly admit to and correct misjudgments? Harrison et al. noted that honesty, humility and a sense of trustworthiness were important attributes contributing to non-profit board chair effectiveness [43]. The ability to openly admit to mistakes is important to both self management and relationship management. Mistakes make emotionally intelligent human beings stronger and give them the opportunity to truly connect with others in honesty and humility.

(12) Are non-profit leaders/decision makers willing to appropriately delegate decision-making authority? Tannenbaum and Schmidt [60] developed a continuum of control and decision-making shared between leaders and followers. At all points on their continuum both the leader and the followers have some control. The amount of control each party has depends on the amount that the followers are able to assume. The leader begins with most of the control over decision-making and gradually passes this over to the followers, as they develop their capability, commitment and maturity. Emotionally intelligent leaders view every decision-making circumstance as an opportunity to develop or improve the relationship with others. Decision-making circumstances also allow the non-profit leader to develop the talents of those around them by delegating decision-making authority and serving as a team member to those to whom decisions have been delegated. When a decision has been delegated it remains critical to support that delegation in all communications.

(13) Are non-profit leaders/decision makers willing to accept the consequences of having delegated or shared the decision-making authority? When decision-making is delegated and things go wrong, the true test of emotional intelligence arises. The emotional intelligence skill applied here is for both the person delegating the decision and the decision maker to acknowledge and learn from the mistake. Additionally, emotionally intelligent non-profit 
leaders/decision makers share credit for good decisions and accept responsibility for bad decisions even though they may not have agreed with the decision.

(14) What are the non-profit leader's/decision maker's attributes in managing conflict? Emotional intelligence is exhibited in conflict settings by seeking first to understand the position and feelings of the other person [59]. Thus in circumstances of conflict, emotionally intelligent non-profit leaders/decision makers are more likely to listen more than they speak and seek opportunities to learn the opinions of others. Being direct about conflicting views is important to demonstrate honesty, and exhibiting compassion in moments of tension develops the trust necessary to foster long-term relationships. Additionally, the emotionally intelligent response in moments of conflict requires an examination of one's own emotions. It is only possible to exhibit self control if one understands the origins of experienced emotions. Emotionally intelligent non-profit leaders/decision makers manage volatility by expressing compassion while exhibiting and furthering the culture of the non-profit organization in the decision-making process [51].

An abbreviated form of the emotional intelligence/decision checklist is included in Exhibit 1. The abridged checklist is designed to serve as a pull-out guide to assist non-profit leaders in their decision-making processes.

\section{Recommendations for Further Research}

Given the distinct missions and goals of non-profit entities, it is clear that a different skill set is required of non-profit leaders. While the literature provides some background on this circumstance, additional research is warranted on the utilization of emotional intelligence within the non-profit leadership setting. The specific research questions that would provide additional insight are:

(1) Do performance differences exist among non-profit CEOs related to the utilization of emotional intelligence? That is to say, are non-profit CEOs who exhibit higher levels of emotional intelligence perceived to be more successful in their job assignments? Intuitively, one would expect this premise to be true, but concrete evidence supporting this notion is needed.

(2) Are non-profit environments, as compared to their for-profit analogs, more favorable to the emotional intelligence skill set?

(3) Are leaders from the for-profit world who exhibit higher levels of emotional intelligence just as likely to experience success when transitioning to the non-profit setting?

(4) Is the institutional environment or the individual skill set more important in determining success when considering the utilization of emotional intelligence skills in the non-profit setting?

(5) Do non-profit leaders who utilize emotional intelligence skill sets experience higher rates of successful decisions as perceived by others within the organization? 


\section{Conclusions}

Every leader of a non-profit organization shares the goal of enhancing the quality of decision-making and the utilization of emotional intelligence skills can assist in the attainment of that goal. Non-profit leaders who are self aware and can accurately and honestly assess their strengths in comparison to others in the organization have the advantage of leveraging the attributes of others in the decision-making process. The ability to assess the potential emotional outcomes and reactions of decisions can empower non-profit leaders/decision makers to predict the sentiment of those affected by decisions, thereby increasing the probability of a more positive decision outcome. The process of building and maintaining relationships is inherently human and requires an emotional perspective and while time consuming, will generate better decision outcomes. Additionally, decisions worth making often generate conflict, and the ability to manage that conflict involves an emotional intelligence skill that can determine the ultimate success of the decision-making process. The utilization of an emotional intelligence checklist can enhance not only the outcome of a decision but also the processes associated with decision-making within the non-profit organization. Finally, additional research is warranted to provide clarity on the impact of the behaviors associated with emotional intelligence on successful outcomes within the non-profit setting.

\section{Conflicts of Interest}

The authors declare no conflict of interest.

\section{References}

1. Lane, J.; Wallis, J. Non-profit organizations in public policy implementation. J. Public Adm. Policy Res. 2009, 1, 141-149.

2. Kramer, R.M. Voluntary Agencies and the Personal Social Services. In the Non Profit Sector, a Research Handbook; Powell, W.W., Ed.; Yale University Press: New Haven, CT, USA, 1987.

3. Milkman, K.L.; Chugh, D.; Bazerman, M. How can decision making be improved? Working Paper 08-102, 2008. Available online: http://www.hbs.edu/faculty/ Publication\%20Files/08-102.pdf (accessed on 28 October 2013).

4. Hilary, G.; Hui, K.W. Does religion matter in corporate decision making in America? J. Financ. Econ. 2009, 93, 455-473.

5. Fernando, M.; Jackson, B. The influence of religion-based workplace spirituality on business leaders' decision-making: An interfaith study. J. Manag. Organ. 2006, 12, $23-39$.

6. Stanovich, K.; West, R.F. Individual differences in reasoning: Implications for the rationality debate. Behav. Brain Sci. 2000, 23, 645-665.

7. Wing, J. Computational thinking and thinking about computing. Philos. Trans. A Math. Phys. Eng. Soc. 2008, 366, 3717-3725.

8. Velasquez, J.D. Modeling Emotion-Based Decision-Making. In Proceedings of AAAI Fall Symposium Emotional \& Intelligent: The Tangled Knot of Cognition, Orlando, FL, USA, 23 October 1998. 
9. Damasio, A. Descartes' Error: Emotion, Reason and the Human Brain; Gosset/Putnam: New York, NY, USA, 1994.

10. Simon, H.A. Motivation and emotional controls of cognition. Psychol. Rev. 1967, 74, $29-39$.

11. Simon, H.A. Designing Organizations for an Information-Rich World. In Computers, Communication and the Public Interest; Greenberger, M., Ed.; John Hopkins Press: Baltimore, MD, USA, 1971; pp. 40-41.

12. Goleman, D.; Boyatzis, R.E.; MacKee, A. Primal Leadership: Learning to Lead with Emotional Intelligence; Harvard Business Press: Boston, MA, USA, 2004.

13. Thach, E.; Thompson, K.J. Trading places: Examining leadership competencies between for-profit vs. public and non-profit leaders. Leadersh. Organ. Dev. J. 2007, 28, 356-375.

14. Freeman, R.E. Strategic Management: A Stakeholder Approach; Cambridge University Press: Cambridge, MA, USA, 2010.

15. Chandler, A.D., Jr. Strategy and Structure: Chapters in the History of the Industrial Enterprise; MIT Press: Cambridge, MA, USA, 1990.

16. Pfeffer, J. Power in Organizations; Pitman: Marshfield, MA, USA, 1981.

17. Lindblom, C.E. The Intelligence of Democracy: Decision Making Through Mutual Adjustment; FreePress: New York, NY, USA, 1965; pp. 38-44.

18. Schwenk, C.R. Conflict in organizational decision making: An exploratory study of its effects in for-profit and not-for-profit organizations. Manag. Sci. 1990, 36, 436-448.

19. Carver, J. Boards That Make a Difference: A New Design for Leadership in Nonprofit and Public Organizations, 3rd ed.; John Wiley \& Sons: New York, NY, USA, 2006.

20. Collins, R. Emotional energy as the common denominator of rational social action. Ration. Soc. 1993, 5, 203-220.

21. Conger, J.; Benjamin, B. Building Leaders; Jossey Bass: San Francisco, CA, USA, 1999.

22. Nadler, D.A.; Tushman, M.L. Beyond the charismatic leader: Leadership and organizational change. Calif. Manag. Rev. 1990, 32, 77-97.

23. Tichy, N.; Devanna, M. Transformational Leaders; John Wiley \& Sons: New York, NY, USA, 1986.

24. Salovey, P.; Grewal, D. The science of emotional intelligence. Curr. Dir. Psychol. Sci. 2005, 14, 281-285.

25. Petrides, K.V.; Pita, R.; Kokkinaki, F. The location of trait emotional intelligence in personality factor space. Br. J. Psychol. 2007, 98, 273-289.

26. Goleman, D. Emotional Intelligence; Bantam Books: New York, NY, USA, 1995.

27. Goleman, D. What makes a leader? Harv. Bus. Rev. 1998, 76, 93-102.

28. Goleman, D. Emotional Intelligence: Perspectives on a Theory of Performance. In The Emotionally Intelligent Workplace; Chermiss, C., Goleman, D., Eds.; Jossey-Bass: San Francisco, CA, USA, 2001.

29. Boyatzis, R.; Goleman, D.; Rhee, K. Clustering Competence in Emotional Intelligence: Insights from the Emotional Competence Inventory (ECI). In Handbook of Emotional Intelligence; Bar-On, R., Parker, J., Eds.; Jossey-Bass: San Francisco, CA, USA, 2000.

30. Taylor, C.A.; Taylor, J.C.; Stoller, J.K. Exploring leadership competencies in established and aspiring leaders: An interview-based study. J. Gen. Intern. Med. 2008, 23, 748-754. 
31. Wang, Y.S.; Huang, T.C. The relationship of transformational leadership with group cohesiveness and emotional intelligence. Soc. Behav. Pers. 2009, 37, 379-392.

32. Antonakis, J.; Ashkanasy, N.M.; Dasborough, M.T. Does leadership need emotional intelligence? Leadersh. Q. 2009, 20, 247-261.

33. Dasborough, M.T.; Ashkanasy, N.M. Emotion and attribution of intentionality in leader-member relationships. Leadersh. Q. 2002, 13, 615-634.

34. Zhou, J.; George, J.M. Awakening employee creativity: The role of leader emotional intelligence. Leadersh. Q. 2003, 14, 545-568.

35. Kouzes, J.M.; Posner, B.Z. The Leadership Challenge; John Wiley \& Sons: New York, NY, USA, 2006; Volume 3.

36. Wheatley, M.J. Leadership and the New Science: Discovering Order in a Chaotic World; Berrett Koehler: San Francisco, CA, USA, 2010.

37. Langley, A. Emotional intelligence: A new evaluation for management development? Career Dev. Int. 2000, 5, 177-183.

38. Dulewicz, V.; Higgs, M. Leadership at the top: The need for emotional intelligence in organizations. Int. J. Organ. Anal. 2003, 11, 193-210.

39. Moore, C.J. Nonprofit staying power. Chron. Philanthr. 2004, 17, $27-29$.

40. Hawkins, J.; Dulewicz, V. The relationship between performance as a leader and emotional intelligence, intellectual and managerial competences. J. Gen. Manag. 2007, 33, 57.

41. Harrison, Y.D.; Murray, V. Perspectives on the leadership of chairs of nonprofit organization boards of directors: A grounded theory mixed-method study. Nonprofit Manag. Leadersh. 2012, $22,411-437$.

42. Harrison, Y.; Murray, V.; Cornforth, C. Perceptions of board chair leadership effectiveness in nonprofit and voluntary sector organizations. VOLUNTAS Int. J. Volunt. Nonprofit Organ. 2013, 24, 688-712. doi:10.1007/s11266-012-9274-0.

43. Harrison, Y.D.; Murray, V.; Cornforth, C. The role and impact of chairs of non-profit boards. In Nonprofit Governance: Innovative Perspectives and Approaches; Cornforth, C., Brown, W.A., Eds.; Routledge: New York, NY, USA, 2013.

44. Morehouse, M.M. An exploration of emotional intelligence across career arenas. Leadersh. Organ. Dev. J. 2007, 2, 296-307.

45. Sevdalis, N.; Petrides, K.V.; Harvey, N. Trait emotional intelligence and decision related emotions. Pers. Individ. Differ. 2007, 42, 1347-1358.

46. Mellers, B.A.; Schwartz, A.; Ritov, I. Emotion-based choice. J. Exp. Psychol. Gen. 1999, 128, 1-14.

47. Winter, K.A.; Kuiper, N.A. Individual differences in the experience of emotions. Clin. Psychol. Rev. 1997, 17, 791-821.

48. Mayer, J.D.; Salovey, P.; Caruso, D. Mayer-Salovey-Caruso Emotional Intelligence Test; Multi-Health Systems Incorporated: Toronto, Canada, 2001.

49. Boyatzis, R.E.; Goleman, D.; Rhee, K. Clustering competence in emotional intelligence: Insights from the emotional competence inventory (ECI). In Handbook of Emotional Intelligence; Bar-On, R., Parker, J., Eds.; Jossey-Bass: San Francisco, CA, USA, 2000. 
50. Bar-On, R. The Era of the "EQ": Defining and Assessing Emotional Intelligence. In Proceedings of the 104th Annual Convention of the American Psychological Association, Toronto, ON, Canada, 11 August 1996.

51. Huy, Q.N. Emotional capability, emotional intelligence and radical change. Acad. Manag. Rev. 1999, 24, 325-345.

52. Lerner, J.; Shonk, K. How anger poisons decision making. Harv. Bus. Rev. 2010, 88, 26.

53. Bazerman, M.; Malhotra, D. It's not intuitive: Strategies for negotiating more rationally. Negotiation 2006, 9, 3-5.

54. Miller, E.G. Understanding emotional reactions for negative services: The impact of efficacy beliefs and stage in process. J. Serv. Res. 2009, 12, 87-89.

55. Vroom, V.H.; Yetton, P.W. Leadership and Decision Making; University of Pittsburgh Press: Pittsburgh, PA, USA, 1973.

56. Tsai, M.-H.; Young, M.J. Anger, Fear and Escalation of Commitment. Cognit. Emot. 2010, 24, 962-973.

57. Wanberg, C.R.; Banas, J.T. Predictors and outcomes of openness to changes in a reorganizing workplace. J. Appl. Psychol. 2000, 85, 132-142.

58. Graen, G.B.; Uhl-Bien, M. Relationship-based approach to leadership: Development of leader-member exchange (LMX) theory of leadership over 25 years: Applying a multi-level multi-domain perspective. Leadersh. Q. 1995, 6, 219-247.

59. Mayer, J.; Caruso, D. The effective leader: Understanding and applying emotional intelligence. Ivey Bus. J. 2002, 67, 1-5.

60. Tannenbaum, R.; Schmidt, W.F. How to choose a leadership pattern. Harv. Bus. Rev. 1973, May, 162-180.

\section{Exhibit 1}

\section{Exhibit 1.}

\begin{tabular}{|ll|}
\hline \multicolumn{2}{|c|}{ Emotional Intelligence-Decision Checklist } \\
\hline $1 . \quad \begin{array}{l}\text { Are you aware of your own leadership and decision-making skills and styles? } \\
\text { Make an honest self assessment of skills and styles, noting the differences in your behaviors and } \\
\text { abilities as compared to others. }\end{array}$ \\
\hline $2 . \quad \begin{array}{l}\text { Would others describe you as inclusive or exclusive in decision-making processes? } \\
\text { Communicate to others when and why inclusive or exclusive methodologies are utilized. }\end{array}$ \\
\hline $\begin{array}{l}\text { Are you confident in your decision-making skills? } \\
\text { Exude confidence in your decision-making style. Acknowledge your weaknesses and have the } \\
\text { confidence to recognize the strengths of others in decision-making. }\end{array}$ \\
$\begin{array}{l}\text { Are you focused on your own interests or are you truly interested in achieving the best } \\
\text { decision results? } \\
\text { Suppress your own desires and interests for the common good. }\end{array}$ \\
$\begin{array}{l}\text { What individuals, groups or constituents will be most affected by the decision? } \\
\text { Contemplate the impact and consequences of a decision before it is made. Play out scenarios of } \\
\text { decisions to determine both their short and long-term consequences and effects. }\end{array}$ \\
\hline
\end{tabular}


Exhibit 1. Cont.

\begin{tabular}{|c|c|}
\hline & onal Intelligence-Decision Checklist \\
\hline 6. & $\begin{array}{l}\text { Are you overly focused on the desire for a speedy result? } \\
\text { Evaluate the consequences of losing trust among workers and teams when speed wins out } \\
\text { over participation. }\end{array}$ \\
\hline 7. & $\begin{array}{l}\text { How will the decision and decision-making process be viewed in retrospect? View actions from a } \\
\text { historical to assess the impact of current decisions through the eyes of constituents. Relive past } \\
\text { decisions to play out the future of current contemplated actions. }\end{array}$ \\
\hline 8. & $\begin{array}{l}\text { How can a decision-making process be utilized to build trust, not only for you, but also among all } \\
\text { the appropriate constituents of the non-profit organization? } \\
\text { Ground yourself in the culture and values of your organization. How does the decision feel? When } \\
\text { in doubt, contrast the impact of a decision and the decision-making process with the fabric of } \\
\text { the organization. }\end{array}$ \\
\hline 9. & $\begin{array}{l}\text { How do you communicate with others engaged in the decision-making process? } \\
\text { Discern which team members require face-to-face dialogue from those that prefer written } \\
\text { communication. An inappropriate communication method can effectively unravel a successful } \\
\text { decision-making process. }\end{array}$ \\
\hline 10. & $\begin{array}{l}\text { Are you willing to adapt to new decision-making processes rather than relying upon the entrenched } \\
\text { processes of the past? } \\
\text { An honest acknowledgement of a need to break with the practices of the past is critical to building } \\
\text { self-confidence, as well as developing the relationships necessary to affect a positive } \\
\text { decision result. }\end{array}$ \\
\hline 11. & $\begin{array}{l}\text { Are you willing to quickly admit to and correct misjudgments? } \\
\text { Openly and quickly admit to mistakes. Mistakes make emotionally intelligent human beings } \\
\text { stronger and give them the opportunity to truly connect with others in honesty and humility. }\end{array}$ \\
\hline 12. & $\begin{array}{l}\text { Are you willing to appropriately delegate decision-making authority? } \\
\text { View every decision-making circumstance as an opportunity to develop or improve the } \\
\text { relationship with others. When appropriate, delegate decision-making authority and serve as a } \\
\text { team member to those to whom decisions have been delegated. }\end{array}$ \\
\hline 13. & $\begin{array}{l}\text { Are you willing to accept the consequences of having delegated or shared the decision-making } \\
\text { authority? } \\
\text { When delegated decisions go wrong, you and the person to whom you delegated the decision } \\
\text { acknowledge and learn from the mistake. Additionally, share credit for good decisions and accept } \\
\text { responsibility for bad decisions even though you may not have agreed with the decision. }\end{array}$ \\
\hline 14. & $\begin{array}{l}\text { What are your attributes in managing conflict? } \\
\text { Seek first to understand the position and feelings of the other person. Examine your own emotions. } \\
\text { Manage volatility by expressing compassion while exhibiting and furthering the culture of the non- } \\
\text { profit organization in the decision-making process. }\end{array}$ \\
\hline
\end{tabular}

(C) 2013 by the authors; licensee MDPI, Basel, Switzerland. This article is an open-access article distributed under the terms and conditions of the Creative Commons Attribution license (http://creativecommons.org/licenses/by/3.0/). 